\title{
Strategic Business and IT Alignment: A Prioritized Theory Diagram
}

\author{
Enrique Silva, Leonel Plazaola, Mathias Ekstedt \\ Industrial Information and Control Systems, Royal Institute of Technology (KTH), SE-10044 Sweden
}

\begin{abstract}
Many academic and practitioners' studies have shown that misalignment or lack of alignment between information technology (IT) and business strategies is one of the main reasons why enterprises fail to exploit the full potential of their IT investments. Furthermore, organizations that have accomplished a high degree of alignment are often associated with better business efficiency and effectiveness performance. Consequently, strategic business and IT alignment (SBITA) has consistently been one of the top concerns of the Chief Information Officer (CIO) in an enterprise.

Despite these facts, there is little consensus on what SBITA really is; there are few documented theories, concepts and operational approaches for identifying, measuring, improving and maintaining the SBITA level in an enterprise.

This paper is based on the strategic alignment model (SAM) proposed by Henderson \& Venkatraman in 1993, which is considered one of the most widespread and accepted models among the alignment community. Basically, all later alignment models and consulting practices start from this model. The SAM consists of a set of alignment sub-topics presented partially in figure \# 3, which have been used for prioritizing the SBITA topic.
\end{abstract}

An extensive literature survey has been carried out and the most relevant and cited references in the field have been categorized according to the sub-topics of the SAM. Doing so provided an indication of how important the alignment community finds the different aspects of SBITA.

\section{BACKGROUND TO THE RESEARCH}

The problem of identification, measurement, improvement and maintenance of the strategic business and IT alignment (SBITA) level has become an increasingly important priority for the CIO and CEO. SBITA may be essential to assure tangible and intangible benefits for the IT investments made by an enterprise. Although SBITA is one of the most central areas for enterprise IT management today, the topic still lacks good decision-making support at the topmanagement level (i.e. CIO and CEO level). See references.

This study is part of an ongoing Enterprise Architecture Research Program (EARP) at the Royal Institute of Technology (KTH) in Stockholm, Sweden. The overall goal of the program is to provide the CIO function with architecture-based tools and planning and decision-making methods for enterprise-wide information systems.

\section{A. Purpose and Scope}

The results presented in this article are part of a larger research project whose goal is to develop a method for assessing the level of strategic business and IT alignment in the frame of Enterprise Architecture. Assessing the SBITA level in an enterprise is a serious challenge for many organizations. It is unclear, for instance, what type of properties should be measured: the communication level between IT and business, the service level agreement performance, the level of human resource skills, the business and IT governance, etc. These aspects would all surely indicate different levels of alignment and different priorities for the same company.

\section{OUTLINE}

The next section presents the paper's main research background, the SAM reference model and the justification for building and prioritizing the SBITA-TD. Section IV describes the transformation of the SAM into a theory diagram. Section V describes the search and review process to select relevant references. Section VI explains the prioritization procedure and presents the prioritized SBITATD. The conclusion, section VII, presents the paper's main results and contributions. See also the logical flow of this work in figure \#1.

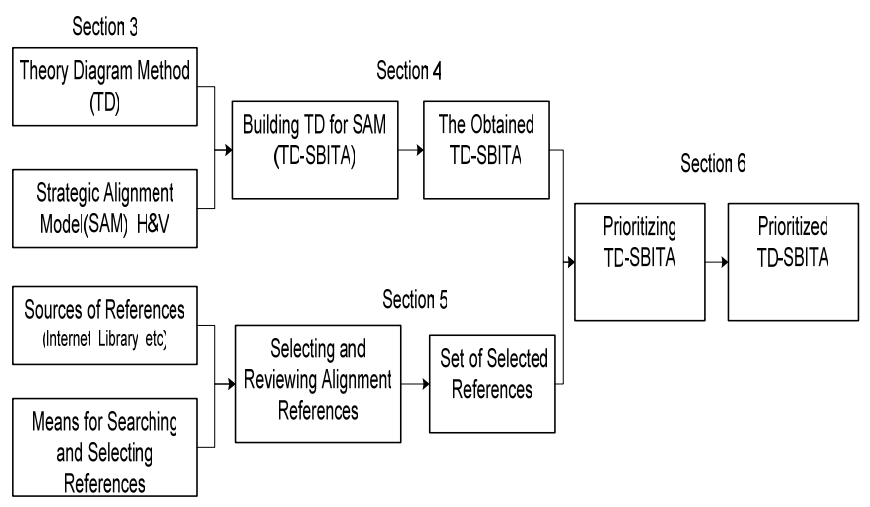

Figure \# 1: Logical Flow of the Work Presented in this Paper

\section{RESEARCH BACKGROUND}

\section{A. The Importance of Assessing the SBITA}

For a number of reasons, contemporary firms operate in a dynamic environment such as new technologies, entrepreneurial ideas, strategic alliances, mergers and acquisitions, and regulatory changes. Key to a wellfunctioning company is an efficiently deployed information technology supporting the business strategies, goals, and needs. 
The importance of SBITA has been reported as an organization-wide issue that directly impacts the company's overall performance. It is claimed to be a necessity to realize benefits from investments in IT. This realization grows in importance as companies strive to link technology and business in the light of dynamic business strategies and continuously evolving information and communication technologies.

Despite the fact that alignment is an issue of utmost importance and that a plethora of articles on the topic exists today, no consensus among academics and practitioners can be found on what alignment is, how it should be defined or measured in the organization, or what measures should be taken to maintain and improve its level. Consequently, the key question about how to accomplish strategic alignment between business and IT in the real world's complex and dynamic environment is still a great unanswered challenge for the CIO and CEO. See references.

\section{B. A Reference Strategic Alignment Model (SAM)}

An extensive literature review on alignment was conducted in this work to identify the works on SBITA that are most generally accepted (by scoring the number of citations). In total, more than 150 articles, books and technical reports were selected and included in the assessment.

The strategic business and IT alignment model most widely cited (279 citations, according to the performed searching process described in section $\mathrm{V}$ of this paper) and used is the one presented by Henderson \& Venkatraman in 1993 [28]. See figure \# 2. This theoretical construct, also known as the strategic alignment model (SAM), describes alignment along two dimensions. The dimension of strategic fit differentiates external focus, directed towards the business environment; and internal focus; directed towards administrative structures. The other dimension of functional integration separates the business and the IT. Altogether, the model defines four domains that must be harmonized to achieve alignment.

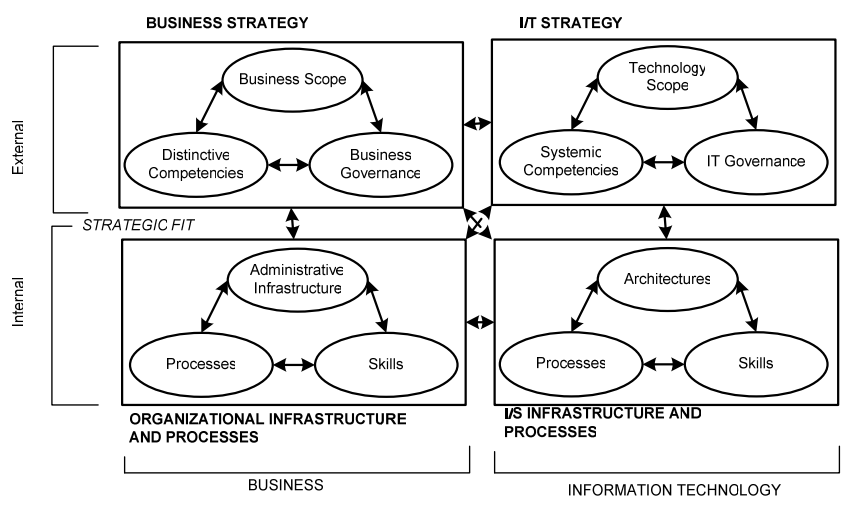

FUNCTIONAL INTEGRATION

Figure \# 2: Strategic Alignment Model (SAM), adopted from Henderson and Venkatraman [28]
The purpose of this paper is to present a nuanced definition of SBITA that highlights the current focus of alignment. Since the SAM is a generally well-accepted framework for alignment, it has been considered suitable to serve as a common reference model. It has thus been used as a structure for categorizing the works of other frequently cited authors collected in the literature review on alignment.

\section{The Need for Defining SBITA}

There is a famous saying that "you cannot control what you cannot measure," and in addition, "...you cannot measure what you cannot define." If we are unable to define and measure alignment, then what we can say about the business effectiveness or about the IT efficiency?

For anyone interested in managing the alignment level in an organization, it is of course of utmost importance to have a clear picture of what alignment is and how it can be concretely defined and assessed. In general, it is conceived that SBITA has to do with the degree of congruence or harmony between the IT strategy and IT infrastructure and the business strategy and organizational infrastructure. Most people also agree that issues such as the communication between IT and business personnel, reporting structures, as well as the actual IT architecture or IT governance, among others, are important factors of alignment.

Several definitions supporting this characterization of alignment are available in the literature: Broadbent \& Weill [14], Chan \& Huff [16], Luftman, Lewis, \& Oldach [47], Maes, Rijsenbrij, Truijens, \& Goedvolk [49], Reich \& Benbasat [62], Tallon \& Kramer [76].

Disagreements, however, are found on the exact extent of such issues and their relative importance to the alignment level. For instance, is human communication more or less important than top management's involvement in IT projects for achieving a highly aligned organization, and should hiring of new employees be considered a part of alignment at all?

Many of the authors referred to in this paper admit that the concept of SBITA is ambiguous, and that very few serious attempts have been made to make the alignment concept more tangible and measurable. Different alternative terms have been used to refer to the alignment issue among the reviewed references, for instance: balance, harmony, coordination, fit, linkage, fusion, relationship, communication, etc. These terms show different perspectives and levels of understanding of the alignment concept. There are a lot of open and unanswered questions, such as: is it possible to define alignment in a unique way?, is alignment an outcome or a process leading to this outcome?, is alignment a dynamic process or an event?, is it possible to measure the alignment level in general?, how does one practice alignment?, what are the most important topics defining or comprising alignment?

According to R. Maes [49], alignment is not clearly defined and offers no handles for management practice. He 
also stated that in order to enhance a practical alignment tool, the following aspects, among others, should at least be considered: 1) "it should start from an unequivocal definition of alignment”; 2) It should consider alignment at different levels, ranging from strategy to implementation; 3) It should attempt measurability. These are part of the important issues that the author of this paper is considering in his assessment through the development of a prioritized SBITA-TD (see section VI.A).

The purpose of this article is thus to categorize and define the topic of alignment more stringently given its current knowledge base. By compiling and reviewing the relevant literature on the subject, the result can give an indication of how important the alignment community finds the different topics and sub topics in its field.

\section{TRANSFORMATION OF THE SAM INTO A THEORY DIAGRAM}

To be able to use the SAM as a framework for categorizing alignment literature we have turned the model into a new format, namely hierarchical theory diagram [34], cf. Figure \# 3. The idea behind theory diagrams (TD) is to decompose intangible and hard-to-measure properties (topics) into more detailed sub-topics. One may thus interpret each level in the subdivided tree as the sum of its underlying sub-levels. This decomposition can of course be performed repeatedly in order to generate a tree-structured hierarchy in any number of levels with the objective of defining, measuring or operationalizing the alignment theory and its key elements. By doing this, a structured, concrete and transparent definition of the subject can be achieved. A TD for alignment thus defines what the alignment community means by this word in terms of other, more specific and concrete properties or topics. According to Johnson [34], a TD facilitates both critical examination and reuse of the theory. A number of criteria to be used when evaluating the quality of a theory diagram are presented below. Relevance. Some theories are relevant to the observer and some are not. Relevance is related to what value it brings to the topic. Relevance is thus an important assessment criterion when generating a TD. Correctness. Except for relevance, the prime aspect of a theory is if it's true or false, i.e. its correctness. The main issues to consider in theory diagrams are whether important properties are missing, whether unimportant ones are present and whether the relations are appropriate. Specificity. Another vital issue is how specific the theory is. With respect to properties, a theory that specifies operationalized properties is more specific, and thus more useful, than one that only specifies intermediate relations. Similarly, a theory that specifies a priori relations is probably more useful than one that only specifies a posteriori relations. Credibility. The credibility of some part of a theory diagram may be assessed in two ways: argue for it yourself, or refer to someone else.

In this case the SAM is transformed into a hierarchical SBITA-TD, which is only a syntactic operation where no "new" categories are added or existing ones excluded. Consequently, the first subdivision of the SAM is strategic fit and functional integration, followed by strategic business fit, strategic IT fit, strategic integration and operational integration.

On the bottom level we end up with 36 sub-topics relating concepts like business and technology scope, architectures, business and IT governance, business process and IT skills, distinctive competencies and administrative infrastructure, etc. all directly mapped to the SAM presented by Henderson and Venkatraman in figure \# 2.

The final theory diagram (SBITA-TD) for SAM is partially presented in figure \# 3 (18 sub-topics from a total of 36).

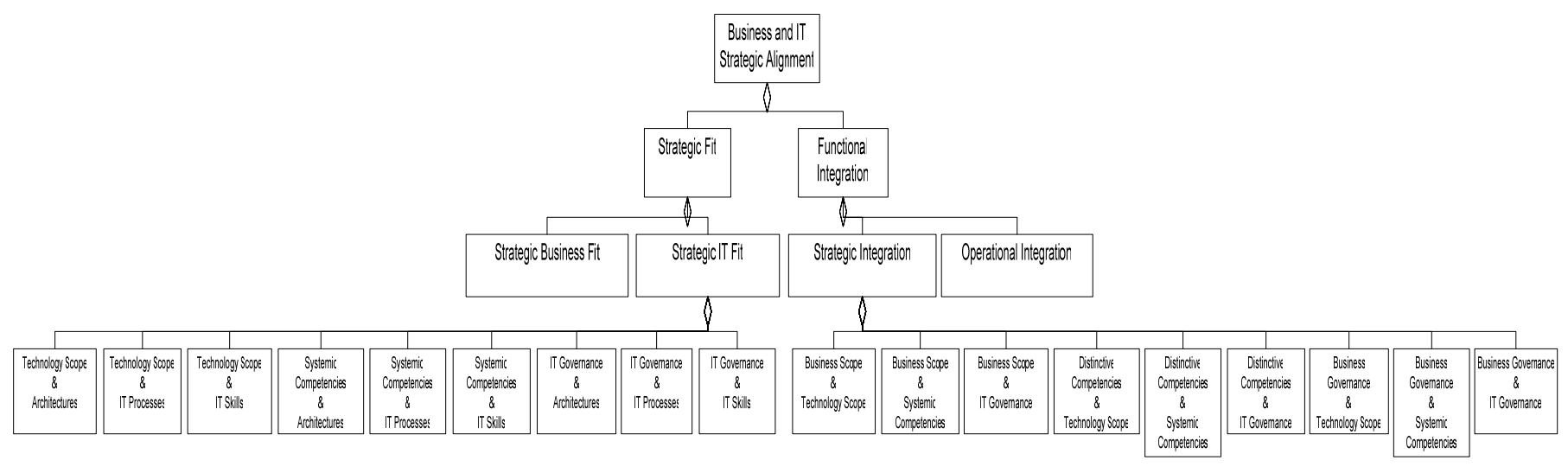

Figure \# 3: SBITA-TD for SAM 


\section{SELECTING AND REVIEWING ALIGNMENT REFERENCES}

The selection of information sources was approached by an extensive literature search over the Internet, using the most important and credible renowned databases. The performed literature review consisted of a broad search of academic and practitioners' information sources of. A set of search key words was used: alignment, business and IT alignment, strategic alignment, IT alignment, IT architecture, IT management, IT and business fit, IT and business fusion, alignment models, measuring IT and business performance, and strategic IT and business planning. References were not only found from direct searches, when highly referenced works were found, but relevant references from these works were also used as sources and criteria for continuing the search process.

All references were selected and classified using the reference author index (RAI), science citation index (SCI), Institute for scientific information (ISI), publications research index (PRI), and based on the search results (citation score) provided by the search engine, i.e. Google Scholar and CiteSeer ${ }^{1}$. The mentioned indexes were used as a means for finding and classifying the more relevant authors' names and papers' titles in the alignment field. The Google Scholar and CiteSeer were used for identifying the citation scores for the selected references or authors.

After the search process, more than 150 documents on the alignment field were found and reviewed. The review process consisted of the abstract and quick reading of all documents in order to determine their relevance in relation to the topics and sub-topics of the SAM. Then a more detailed selection was performed and a more in-depth analysis was made of the 89 most relevant (considering the topic and sub-topics of the SAM), highly cited and credible research papers, books and technical professional and consultant reports.

These 89 selected references were classified in a database built to facilitate the review and data extracting process, containing the following fields: index number, author names, title, key words, citation score, and definitional, cause and effect and compositional statements.

For each of the 89 references a summary of $75 \%$ of their content was generated using a summarizer tool (Copernic Summarizer), ${ }^{2}$ and a set of key words associated with the properties and components included in SAM were defined as inputs for this tool, for example: strategic business fit, strategic IT fit, strategic integration, operational integration, functional integration,

\footnotetext{
${ }^{1}$ http://scholar.google.com; http://citeseer.ist.psu.edu; http://library.dialog.com; www.isinet.com

${ }^{2}$ For details see www.copernic.com
}

organizational infrastructure and process, IT/IS infrastructure and process, business and technology scope, distinctive and systemic competencies, business and IT governance, administrative infrastructure, IT architecture, business and IT process, business and IT skills.

Using sophisticated statistical and linguistic algorithms, Copernic Summarizer analyzes text of any length, generates a list of the key concepts contained in the original documents (Word, PDF and others) and creates summaries composed of the most relevant sentences. The algorithm is fundamentally based on searching a chain of key words defined by user and some linguistic criteria for selecting specific sentences or statements containing the defined set of key words, starting from the previous point and ending with the closer next point i.e. taking an entire sentence.

Once the summary was obtained, the summarizer tool allowed us to highlight the main defined key words or concepts along the text and obtaining the summary file in a ".doc" or ".txt" form. Then, an own program (a software application) was developed by the author in order to review the obtained summary and facilitate the selection procedure of different types of statements (definitional, cause and effect and compositional). After all automatic process, the finally selected statements (190 in total) were completely read and analyzed by the author with the validation and re-classification objective and after that they were stored in a database. The mentioned software application and database will be presented and referred during the paper oral presentation.

The main goal of the previous described work was to identify and classify for each of the summary these three different types of statements: definitional (define the concept of SBITA in general or partially), cause and effect (define cause and effect relationship between two components or factors affecting SBITA), and compositional (identify components and their relationship with different SBITA sub-topics). The purpose of this was to get input numerical data and percentage for prioritizing the SBITA-TD in a more efficient, reliable and credible way.

An average of 5 statements for each of the selected 89 references, i.e. a total of 445 statements were found and selected. All statements were then reviewed and a 190 of them, most relevant and representative ones, were used to make the SBITA prioritization. Considering the built SBITA-TD in section IV and all obtained data and information from the reviewed references, we are prepared to start with the procedure of the SBITA-TD prioritization.

\section{PRIORITIZING THE SBITA-TD}

\section{A. Theory-based Prioritization}

In this work a topic of SBITA has been prioritized according to the focus of the identified literature. In order to develop a relevant and trustworthy result of such a theory-based prioritization, it is of utmost importance to consider: 1) completeness, i.e. the more references the better; 2 ) the fit of the 
references with respect to the intended scope, i.e. they should deal with the topic of alignment; 3) how well accepted the references are, i.e. the less controversial the better; and 4) the degree of operationalization, i.e. their practical applicability in the real world [34].

In relation to the first and second points, we can argue that a broad and credible reference search was performed by using a set of relevant alignment criteria and key words as explained in the previous chapter. This way we assured a high degree of completeness and fitness to the alignment scope. To assure a reasonable acceptance level of the references, as mentioned in point three, they were selected by citation scores in the alignment field. The fourth criterion, the degree of operationalization, was an important criterion not only for academic but also for practitioners' reviewed references. Therefore we can argue that the applied prioritization procedure fulfills the four mentioned requirements for assuring its credibility to a high degree.

The purpose of obtaining a prioritized TD based on SAM, in this case the SBITA-TD, is to categorize and define the topic of alignment more stringently given its current knowledge base. This prioritized SBITA-TD should give indications on how important the alignment community finds the different topics and sub-topics in the alignment field.

\section{B. The Prioritization of SBITA-TD}

The SBITA-TD prioritization process consists of weighting the importance of the alignment sub-topics presented by the most relevant and cited alignment references found. Given the large set of relevant references, it is then possible to picture how the alignment community as a whole is prioritizing its area.

Moreover, it is reasonable to use this distribution as a norm for a general definition of alignment, since it is the de-facto prioritization made by experts in the field.
The weighting procedure consists of assessing each of the selected references and its corresponding statements, identifying general and specific alignment topics and relating them to the levels and sub-topics presented in the SBITA-TD. Once a topic is identified and related to a specific sub-topic, a value weight of "1" is assigned to that sub-topic in the SBITA-TD. The process is repeated for each assessed reference, and then all weights are accumulated and written in the corresponding subtopic (in the bottom level of the SBITA-TD). At the end of this weighting process, all accumulated values in all 36 sub-topics are added together.

That makes it possible to calculate percentages for each subtopic, dividing the accumulated value in each by the calculated total. To get the percentage for each of the four boxes of the next level up in the SBITA-TD, the corresponding percentages are added.

The prioritized SBITA-TD thus shows in percentage form the level of importance of different key alignment topics or properties presented by the relevant selected sources. The resulting numbers and percentages were then translated into weights of importance for the corresponding levels, categories or topics in the SBITA-TD.

It is now possible to identify how the most relevant and credible references are defining the alignment construct and which are the more mentioned topics or domains based on the SAM.

\section{See the example in figure \# 4 and figure \# 5.}

Moreover, it is possible to highlight deviations or focus variations of different alignment theories and concepts among the selected and used references, which are not immediately apparent when looking at the different references or theories separately.

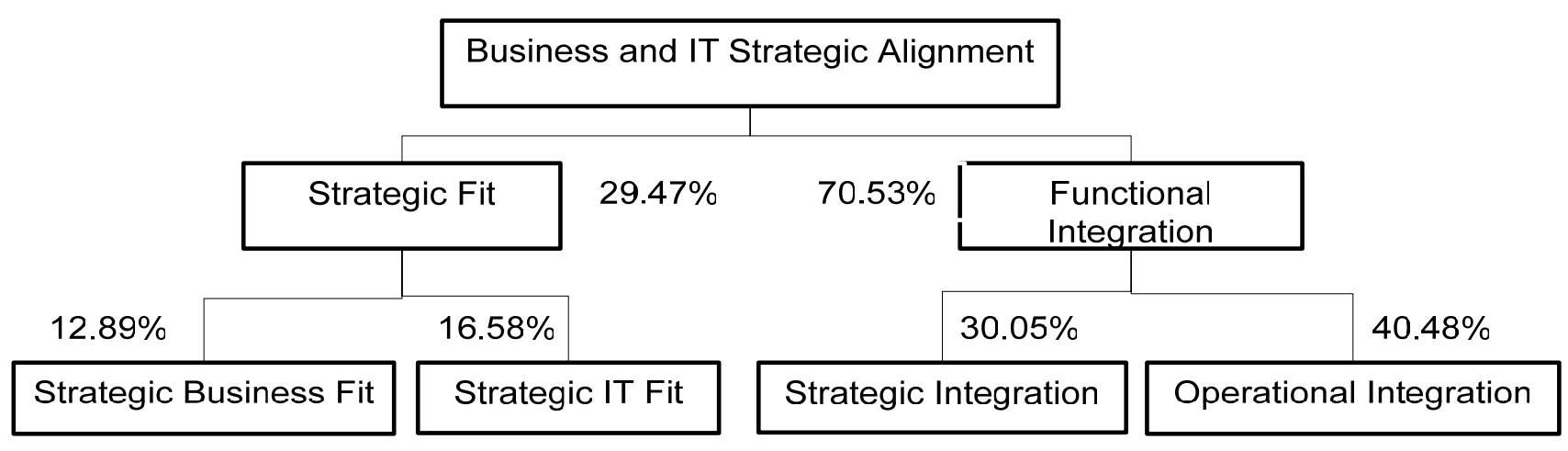

Figure \# 4: Example of a Prioritized SBITA-TD based on SAM (showing only three of four levels) 


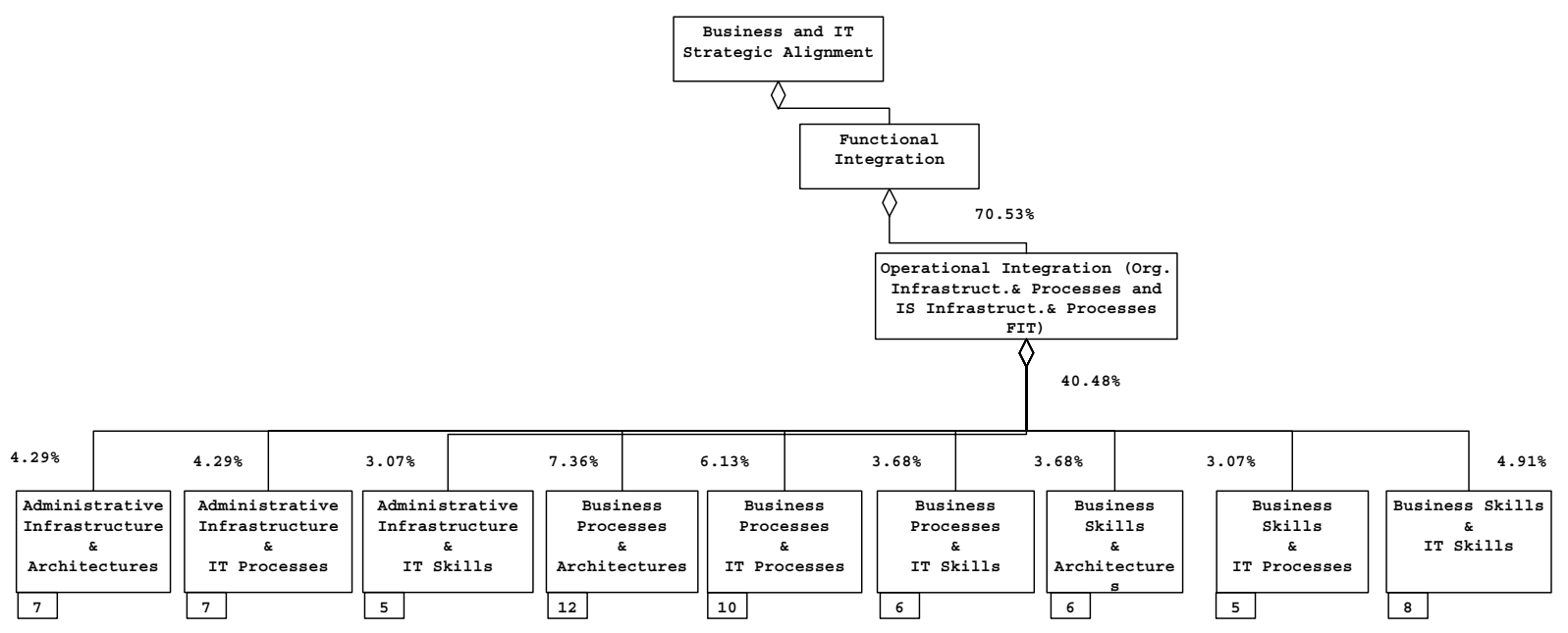

Figure \# 5: Example of a Prioritized SBITA-TD, Showing 9 Sub-Topics for the Operational Integration Topic.

\section{CONCLUSIONS}

The prioritized SBITA-TD should give indications of how important the alignment community finds the different topics and sub-topics in the alignment field.

One of the relevant findings presented in this paper, after obtaining the SBITA-TD, was the fact that most of the literature in the strategic alignment field is putting its efforts into the strategic integration and operational integration in the bottom level of the SBITA-TD (figure \# 5); i.e. the functional integration topic represents $70.53 \%$ of importance in the effort to define or evaluate the business and IT strategic alignment. On the other hand, the strategic fit topic represents only $29.47 \%$. By having this percentage reference, a more structured, tangible and transparent definition of the alignment concept can be obtained and the operationalization process for different sub-topics of the SBITA-TD can be achieved in an easier and clearer way.

The prioritized SBITA-TD presented can make an important contribution to the current theoretical and practical assessment frameworks in the business and IT strategic alignment field, considering the numerical results presented in order to improve their approach to the alignment topic.

A deeper and broader quantitative and qualitative analysis based on this work is planned for coming publications in order to refine the numeral results, thus increasing the credibility of the methodology and findings.

\section{ACKNOWLEDGMENTS}

The authors would like to thank Dr. Pontus Johnson at $\mathrm{KTH}$, Stockholm, Sweden, for his continuous support and encouragement in keeping the pace and track on the alignment research field.

\section{REFERENCES}

[1] Al-Mashsari, M., Zairi and M., Creating a Fit Between BPR and IT Infrastructure: A Proposed Framework for Effective Implementation, The International Journal of Flexible Manufacturing Systems 12, 2000, pp. 253-274.

[2] Beer, M., et. al., Strategic Management as Organizational Learning: Developing Fit and Alignment through a Disciplined Process, Long Range Planning, 2005.

[3] Beer, Michael, Voelpel, Sven, Marius, L., et al, Strategic Management as Organizational Learning: Developing Fit and Alignment through a Disciplined Process, Article in Press, 2005.

[4] Beer M., Building Organizational Fitness, in S. Chowdhury (ed.), Organizations 21C, Financial Times Prentice Hall, NJ, (2002), pp. 311330.

[5] Beer M., Eisenstat, R. A. and Spector, B. A., The Critical Path to Corporate Renewal, Harvard Business School Press, Boston, MA (1990).

[6] Bergeron, F., Raymond, L. and Rivard S., Ideal Patterns of Strategic Alignment and Business Performance, Information and Management 41, 2004, pp. 1003-1020.

[7] Bergeron, F., Strategic Alignment and Business Performance: Operationalizing and Testing a Covariation Model, Cahier de la Chire de gestion stratégique des technologies de l'information No. 02-01, 2002.

[8] Bergeron, -F. and Raymond, L., The Contribution of IT to the Bottom Line: a Contingency Perspective of Strategic Dimensions, in Proceedings of the $16^{\text {th }}$ International Conference on Information Systems, Amsterdam, 1995, pp. 167-181.

[9] Boar B., Strategic Planning for Information Technology, second edition, John Wiley, 2001.

[10] Boar B., Practical Steps for Aligning Information Technology with Business Strategies: How to Achieve a Competitive Advantage, Wiley, N.Y., 1994.

[11] Brancheau J. C. et al., Key Issues in Information Systems Management: 1994-95 SIM Delphi Results. MIS Quarterly, 20 (2), June, 1996.

[12] Broadbent, $M$ and Weill, P., Developing Business and Information Strategy Alignment: A Study in the Banking Industry, Proceedings of the Twelfth International Conference on Information Systems, New York, New York, (December 1991), pp. 293-306.

[13] Broadbent, M., Butler, C. and Hansell, A., Business and Technology Agenda for Information Systems Executives, International Journal of Information Management 14 (6), 1994, pp. 411-426. 
[14] Broadbent, M. and Weill, P., Improving Business and Information Strategy Alignment: Learning from the Banking Industry, IBM Systems Journal, (1993), 32, pp. 162-179.

[15] Burn, J. M., and Szeto, C., A Comparison of the Views of Business and IT Management on Success Factors for Strategic Alignment, Information and Management, 37(4), 2000, pp. 197-216.

[16] Chan, Y. E., Huff, S.L., Barclay, D. W., and Copeland, D. G., Business Strategy Orientation, Information Systems Orientation and Strategic Alignment, Information Systems Research, 8: 2 (1997), pp. $125-150$

[17] Ciborra Claudio, De Profundis? Deconstructing the Concept of Strategic Alignment, Scandinavian Journal of Information Systems 9(1), 1997, pp. 67-82.

[18] Coughlan Jane, Lycett, M. and Macredie, R.D., Communication Issues in Requirements elicitation: A Content analysis of stakeholder experiences, Information and Software Technology, 45(8), 2003, pp.525-537.

[19] Coughlan Jane, Lycett, Mark and Macredie, Robert, Understanding the Business-IT Relationship, International Journal of Information Management 25, 2005, pp. 303-319.

[20] Cragg, P., King, M. and Husnayati H., IT Alignment and Firm Performance in Small Manufacturing Firms, Journal of Strategic Information Systems 11, 2002, pp. 109-132.

[21] Cragg, P. and King, M., Small Firm Computing- Motivators and Inhibitors, MIS Quarterly 17, 1993, pp. 47-60.

[22] Davis, G.B. and Olson, M. H., Management Information Systems, $2^{\text {nd }}$ ed., McGraw-Hill Inc (1985).

[23] Eardley A. et al., The linkage between IT and Business Strategy in Competitive systems: A Reappraisal of some "classic" cases using a Competition Analysis Framework, International Journal of Technology Management, 11 (3-4), 1996, pp. 395-411.

[24] Ekstedt, et al., Consistent Enterprise Software System Architecture for the CIO - A utility-Cost Approach, Proceedings of HICSS-37, 2004.

[25] Grembergen W. et al., Aligning Business and IT through the Balanced Scorecard at a major Canadian Financial Group: Its status measured with an IT BSC maturity model, in: Proceeding of the $34^{\text {th }}$ Hawaii International Conference on System Sciences , January 2001, Maui, HL.

[26] Hale, Andrea J., Cragg, Paul B, Measuring Strategic Alignment in Small Firms, IEEE, 1996, pp. 127-135.

[27] Haveman, E., Organization for Business Objectives, Long Range Planning, 1996, pp. 14-17.

[28] Henderson, J. and Venkatraman, N., Leveraging Information Technology for Transforming Organizations, IBM Systems Journal, 32, (1993), pp. 4-16.

[29] Henderson, J. C., Plugging into Strategic Partnerships, Sloan Management Review, 31:3 (Spring 1990), pp. 7-18.

[30] Henderson, J. C., and Sifonis, J., Understanding the Value of IT Planning: Understanding Consistency, Validity and IT Markets, MIS Quarterly 12:2 (June 1998), pp. 187-200.

[31] Henderson, J. C. and Venkatraman, N., Strategic Alignment: A Model for Organizational Transformation Through Information Technology, in Transforming Organizations, ed. Thomas A. Kocham and Michael Ussem. Oxford University Press, 1992.

[32] Jarvenpaa, S. L. and Ives, B., Organizational Fit and Flexibility: IT Design Principles for a Globally Competing Firm, in C. C. Snow (Editor), Strategy, Organization Design and Human Resource Management, Volume 3, Greenwich, Connecticut: JAI Press Inc, 1994, pp. 1-39.

[33] Johnson P., Enterprise Software System Integration - An Architectural Perspective, Ph.D. Thesis, Royal Institute of Technology (KTH), Stockholm, 2002.

[34] Johnson P., et al., Using Enterprise Architecture for CIO DecisionMaking: On the importance of theory, in the Proceedings of the 2nd Annual Conference on Systems Engineering Research (CSER), April 15-16, 2004.
[35] Johnsson N. et al., An Organization-wide Approach for Assessing Strategic Business and IT Alignment, in Proceedings of the PICMET 2005, Portland, Oregon, USA, July 2005.

[36] Jordan, E., Tricker, B., Information strategy: alignment with organization structure, Journal of Strategic Information Systems 4 (4), 1995, pp. $357-$ 382.

[37] Josi, M., Kathuria, R. and Porth, S., Alignment of strategic priorities and performance: an integration of operations and strategic management perspectives, Journal of Operations Management 21, 2003, pp. 353-369.

[38] Kearns, G. S. and Lederer, A. L., Alignment of Information Systems Plans with Business: The impact of Competitive Advantage, AIT Conference Proceedings, Phoenix, 1997.

[39] Kearns, G. S. and Lederer, A.L., Strategic IT Alignment: A Model for Competitive Advantage, Proceedings of the $22^{\text {nd }}$ International Conference of Information Systems, New Orleans, 2001.

[40] Kefi, Hajer, Kalika, M., Survey of Strategic Alignment Impacts on Organizational Performance in International European Companies, Proceedings of the $38^{\text {th }}$ Hawaii International Conference on Systems Sciences, 2005.

[41] Khandelwal, V. K. and Ferguson, J. R., Critical Success Factors and the Growth of IT in Selected Geographic Regions, Proceedings of the $32^{\text {nd }}$ Hawaii International Conference on Systems Sciences, 1999.

[42] Kim S. H., D.H. Jang, D. H. Lee, et al, A Methodology of Constructing a Decision Path for IT investment, Journal of Strategic Information Systems 9, August 2000, pp. 17-38.

[43] King, W., Strategic Planning for MIS, MIS Quarterly, 2(1). 1978, pp. $27-$ 37.

[44] Kleiner, N., Delta analysis with workflow logs: aligning business process prescriptions and their reality, Springer-Verlag London Limited, 2005.

[45] Luftman, J. N., Applying the Strategic Alignment Model, in J.N. Luftman (ed.), Competing in the Information Age: Strategic Alignment in Practice, Oxford: Oxford University Press, 1996, pp. 43-69.

[46] Luftman, J. N., Assessing IT/Business Alignment, Information Systems Management, 20(4), 2003, pp. 9-15.

[47] Luftman, J. N., Lewis, P.R. and Oldach, S.H., Transforming the Enterprise: The Alignment of Business and IT Strategies, IBM Systems Journal 32(1), 1993, pp. 198-221.

[48] Luftman, J. N., Papp, R. and Brier, T., Enablers and Inhibitors of BusinessIT Alignment, Communications of the Association for Information Systems 1(11), 1999, pp. 1-32.

[49] Maes, R., Rijsenbrij, D., Trujiens, O., et al, Redefining Business-IT Alignment through a Unified Framework, White Paper, Universiteit van Amsterdam, Cap Gemini Institute, 2000.

[50] Maheshkumar, P.J., Ravi, K. and Stephen J. Porth, Alignment of Strategic Priorities and Performance: an Integration of Operations and Strategic Management Perspectives, Journal of Operations Management 21, 2003, pp. 353-369.

[51] Miller, Jonathan, Information Systems Effectiveness - An Inter-Industry Comparison, in Information Systems in Practice and Theory, North Holland: Elsevier Science Publishers B.V., 1988, pp. 87-107.

[52] Miller, Jonathan, Measuring and Aligning Information Systems with the Organization, Information and Management 25, 1993, pp. 217-228.

[53] Papp, R., Luftman, J.N. and Brier, T., Strategic Alignment: Perspectives, Assessments, Enablers and Inhibitors, Proceedings of the Tenth Annual Conference of the International Academy for Information Management, 1995, pp. 163-172.

[54] Peppard, J., Bridging the Gap between the IS Organization and the Rest of the Business: Plotting a route. Information Systems Journal, 11(3), 2001, pp. 249-270.

[55] Peppard, J. and Ward, J., Mind the Gap: Diagnosis the relationship between the IT Organization and the Rest of the Business, Journal of Strategic Information Systems, 8(2), 1999, pp. 29-60.

[56] Plazaola L., Silva E., et al., A Theory-Based Meta Model for Strategic Business and IT Alignment Assessment, CSER 2006, Los Angeles, California.

[57] Pollais, Y. A., Patterns of co-alignment in information-intensive organizations: Business Performance through Integration strategies, 
International Journal of Information Management, 23(6), 2003, pp. 469-492.

[58] Powell, T. C. and Dent-Micallef, Anne, Information Technology as Competitive Advantage: The Role of Human, Business, and Technology Resources, Strategic Management Journal, 18:5, (1997), pp. 375-405.

[59] Reich, B. H. and I. Benbasat, A Model for the Investigation of Linkage between Business and Information Technology Objectives, Research in Strategic Management and Information Technology, JAI Press Inc, 1(1994): pp. 41-72.

[60] Reich, B.H., Y. E. Chan, and G. Bassellier, Investigating IT Competence in Business Managers, SIM Workshop, Atlanta, Georgia (December 1997).

[61] Reich, B.H. and I. Benbasat, Measuring the Linkage between Business and Information Technology Objectives, MIS Quarterly, 20:1 (March, 1996): pp. 55-81.

[62] Reich, B.H. and I. Benbasat, Factors that Influence the Social Dimension of Alignment between Business and Information Technology Objectives, December 5, 1998.

[63] Rumelt, R., Toward a Strategic Theory of the Firm, in R. Lamb, Competitive Strategic Management, Prentice-Hall, Englewood Cliffs, NJ, (1984), pp. 556-570.

[64] Sabherwal, R., Hirschheim, R. and Goles, T., The Dynamics of Alignment: Insights form a Punctuated Equilibrium Model, Organization Science, 12, 2(2001), pp. 179-197.

[65] Sabherwal, R. and Chan, Y., Alignment between Business and IS Strategies: A Study of Prospectors, Analyzers and Defenders, Information Systems Research, 12, 1(2001), pp. 11-33.

[66] Sabherwal, R. and King, W., Toward a Theory of Strategic Use of Information Services, Information and Management 20, (1991), pp. 191-212.

[67] Sabherwal, R. and Kirs, P., The Alignment between Organizational Critical Success Factors and Information Technology Capability in Academic Institutions, Decision Sciences, 25, 2(1994), pp. 301-330.

[68] Sankar, C., Apte, U., and Palvia, P., Global Information Architectures: Alternatives and Tradeoffs, International Journal of Information Management 13, 1993, pp. 84-93.

[69] Sauer, C. and Yetton, P. W., Steps to the future: Fresh Thinking on the Management of IT-based Organizational Transformation, San Francisco, CA: Jossey-Bass, 1997.

[70] Silva E., "Evaluating IT Investments: A Business Process Simulation Approach", Licentiate Thesis, Royal Institute of Technology (KTH), Stockholm, Sweden 2003.

[71] Silva E., et al., "How to Identify and Measure the Level of Alignment between IT and Business Governance", in Proceedings of the PICMET 2005, Portland, Oregon, USA, July 2005.

[72] Tallon, P., Kraemer, K.L. and Gurbaxani, V., Fact or Fiction: The Reality behind Executives, Perceptions of IT Business Value, Working Paper, CRITO, University of California, Irvine, 1998.

[73] Tallon, P., Kraemer, K.L. and Gurbaxani, V., Executives' Perceptions of the Contribution of Information Technology to Firm Performance: A Process-oriented Approach, Journal of Management Information Systems, (2000), 16(4), pp. 137-165.

[74] Tallon, P., Kraemer, K.L. and Gurbaxani, V., Executives' Perceptions of the Business Value of Information Technology: A
Process-oriented Approach, Journal of Management Information Systems, 16, 4(2000), pp. 165-173

[75] Tallon, P., Kraemer, K.L. Gurbaxani, V., et al., A Multidimensional Assessment of the Contribution of IT to Firm Performance, in Proceedings of the $5^{\text {th }}$ European Conference on Information Systems, Cork, Ireland, (1997), pp. 846-867.

[76] Tallon, P. and Kraemer, K., A Process-oriented Assessment of the Alignment of Information Systems and Business Strategy: Implications for IT Business Value, Proceedings of the Association for Information Systems Americas Conference, Baltimore, Maryland, August (1998), pp. 14-16.

[77] Tallon, P. and Kraemer, K., Using Flexibility to Enhance the Alignment between Information Systems and Business Strategy: Implications for IT Business Value, April 20, 2003.

[78] Tallon P. and Kraemer, K., Investigating the Relationship between Strategic Alignment and IT Business Value: The Discovery of a Paradox, 2003.

[79] Teo, T. and King, W., Assessing the Impact of Integrating Business Planning and IS Planning, Information and Management, 30, 1996, pp. 309-321.

[80] Teo, T. and King, W., Integration between Business Planning and Information Systems Planning: an Evolutionary-contingency Perspective, Journal of Management Information Systems 14(1), 1997, pp. 185-214.

[81] Venkatraman, N., Strategic Orientation of Business Enterprises: The Construct, Dimensionality, and Measurement, Management Science, 1989, 35(8), pp. 942-962.

[82] Venkatraman, N., The Concept of Fit in Strategy Research: Toward Verbal and Statistical Correspondence, Academy of Management Review, 19889, 14(3), pp. 423-444.

[83] Venkatraman, N., Henderson, J. C. and Oldach, S.H., Continuous Strategic Alignment: Exploiting IT Capabilities for Competitive Success, European Management Journal, 11, 2(1993), pp. 139-149.

[84] Venkatraman, N. and Prescott, J. E., Environment-Strategy Co alignment: An Empirical Test of its Performance Implications, Strategic Management Journal, 11, 1(1990), pp. 1-23.

[85] Venkatraman, N. and Ramanjuam, V., Measurement of Business Economic Performance: An examination of Method Convergence, Journal of Management, 13(1), 1987, pp. 109-122.

[86] Ward, P. T. and Bickford, D.J., Configurations of Manufacturing Strategy, Business Strategy, Environment and Structure, Journal of Management 22(4), 1996, pp. 597-626.

[87] Weill, P., The Role and Value of Information Technology Infrastructure: Some Empirical Observations, in Strategic Information Technology Management: Perspectives on Organizational Growth and Competitive Advantage (Editors: R.D. Banker, R. J. Kauffman, M. A. Mahmood), Harrisburg, PA: Idea Publishing Group, 1993.

[88] Weill, P., Subramani, M. and Broadbent, M., Building IT Infrastructure for Strategic Agility, Sloan Management Review, 44, 1(2002), pp. 57-65. Proceedings of the $38^{\text {nd }}$ Hawaii International Conference on Systems Siences-2005.

[89] Weill, P. and Broadbent, M., Leveraging the New Infrastructure: How Market Leaders Capitalize on Information Technology, Harvard Business School Press: Cambridge, MA, 1998. 